Abstracta Iranica Abstracta Iranica

Revue bibliographique pour le domaine irano-aryen

Volume 26 | 2005

Comptes rendus des publications de 2003

\title{
«A Safavid Poet in the Heart of Darkness: The Indian Poems of Ashraf Mazandarani ». Iranian Studies, 36, 2, (2003), pp. 197-212.
}

Ève Feuillebois-Piérunek

\section{(2) OpenEdition}

1 Journals

Édition électronique

URL : http://journals.openedition.org/abstractairanica/1861

ISSN : 1961-960X

Éditeur :

CNRS (UMR 7528 Mondes iraniens et indiens), Éditions de l'IFRI

Édition imprimée

Date de publication : 15 mai 2005

ISSN : 0240-8910

Référence électronique

Ėve Feuillebois-Piérunek, « «A Safavid Poet in the Heart of Darkness: The Indian Poems of Ashraf Mazandarani ». Iranian Studies, 36, 2, (2003), pp. 197-212. », Abstracta Iranica [En ligne], Volume 26। 2005, document 351, mis en ligne le 07 décembre 2005, consulté le 25 septembre 2020. URL : http:// journals.openedition.org/abstractairanica/1861

Ce document a été généré automatiquement le 25 septembre 2020.

Tous droits réservés 


\section{« A Safavid Poet in the Heart of Darkness: The Indian Poems of Ashraf Mazandarani ». Iranian Studies, 36, 2, (2003), pp. 197-212.}

Ève Feuillebois-Piérunek

L'article étudie l'ambivalence des sentiments que l'exil inspire aux lettrés émigrés volontaires en Inde à l'époque safavide : attirance par la richesse et le prestige qu'ils espèrent y trouver, mais répulsion à l'égard du climat, de la culture et de la société du pays d'accueil. Ashraf (m.1702) fut l'un de ces hommes : appuyé par Sa'ib, il servit Aurangzib et Shah 'Alam. Comme les autres poètes persans, il dit peu de bien de l'Inde, mais se distingue par son analyse des différentes réactions face à ce pays. Il exprime ses propres sentiments au contact de ce pays, ses complexes et ses contradictions vis-à-vis de l'Iran, les raisons de son exil volontaire. L'article contient aussi une sommaire comparaison avec le vécu des Européens au $19^{\mathrm{e}} \mathrm{s}$. en Inde.

\section{INDEX}

Thèmes : 11.1.1. Littérature persane classique nompropre Safavides, Ashraf Mazandarani

Mots-clés : Poésie classique

Keywords : Traditional poetry 
AUTEURS

ÈVE FEUILLEBOIS-PIÉRUNEK

Sorbonne Nouvelle - Paris III 